\title{
AIR-BORNE ALLERGENS
}

\author{
$B y$ H. A. HYDE, M.A., F.L.S. \\ Keeper, Department of Botany, National Museum of Wales, Cardiff. \\ and D. A. Williams, M.D., F.R.C.P., M.Sc. \\ St. David's Hospital, Cardiff
}

Hay fever occurs in some 0.5 per cent. of the population of Great Britain and pollen asthma develops in some 40 per cent. of cases of grass pollen hay fever (Williams, r958). In London, Pearson (1958) found sensitivity to grass pollen in 18 per cent. of 625 asthmatics. At Cardiff, grass pollen hay fever preceded asthma in 5 per cent. of 487 asthmatics (Williams et al., I958), and a further 6 per cent. developed grass pollen hay fever after the onset of their asthma.

Mould spores were a dominant cause of asthma at Cardiff in some 5 per cent. of 627 adult asthmatics, and it was considered that they might play a subsidiary part in many others (Hyde, Richards and Williams, I956). The mould sensitive cases were all patients worse in the summer and in many their asthma was confined to the summer months.

In asthma and hay fever the most important group of allergens are the inhalants, and none lend themselves better to careful clinical and scientific study than air-borne pollens and fungus spores.

Before clinicians can investigate which pollens or fungus spores are causing allergic symptoms, they must know which kinds occur in the air and at what seasons: the selection of extracts for skin testing depends on this knowledge. Moreover, skin tests will only indicate the presence or absence of skin-sensitizing antibodies, and their results can only be correctly interpreted therefore in the light of an attempted correlation between the times of occurrence or of exacerbation of symptoms and the times of occurrence or abundance of some of any of the various kinds of pollen or fungus spores in the air. Numerous aerobiological studies of pollen and fungus spores have been made during the past 20 years, in Great Britain (and other countries), to this end.

\section{Pollen Studies}

The first to prove a causal relationship between pollen and allergic disease was Charles Blackley
(1873). Pollen morphology has been studied intensively in recent years, notably by Wodehouse (1935) in America, Erdtman (1943, 1952) is and Faegri and Iversen (1950) on the Continentos of Europe, and for western Europe there nowo exists a photographic atlas of air-borne pollen grains which contains descriptions and photomicrographs of 92 species caught from the air in Great Britain (Hyde and Adams, 1958). It is now possible to identify 99 per cent. of all (undamaged) pollen grains caught from the कृष्ठु Regular pollen and spore trapping, centred \&n Cardiff, has been carried on in Great Britäno since I94I (Hyde, 1955). One (or, for some years two) station(s) have been operated continuously a Cardiff from 1942 onwards until the presen time and I4 out-stations ranging from Aberdeer in the north to the Isles of Scilly in the south $\overrightarrow{\vec{B}}$ for periods of one to five years. These stations have been situated in both rural and urban dis? tricts (including central London) in the lowlands: in mountain areas, and on off-shore islands ing Wales and on an Atlantic lighthouse

Pollen grains are caught and stained by trapping them on microscope slides, 3 in. by 1 in., thinl smeared with glycerin jelly containing a suitable dye. The coated slide may be exposed hori zontally under a cover such as a Hyde an $\$$ Williams' shelter for 24 hours ('gravity' slide method), or it may be placed in a slit samplez. such as the automatic volumetric spore trafs (A.V.S.T.) devised by Hirst (1952). Either way̆, the slide after exposure is mounted and scanned The gravity slide is simpler to operate, but the A.V.S.T. is more efficient for it gives numbers of spores per unit volume of air sampled and it cate be used to determine hour-to-hour variations is the load.

As the result of botanical studies made by the

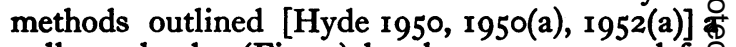
pollen calendar (Fig. I) has been constructed fo Cardiff which is applicable to Great Britain as $\mathbb{Q}$ whole. 


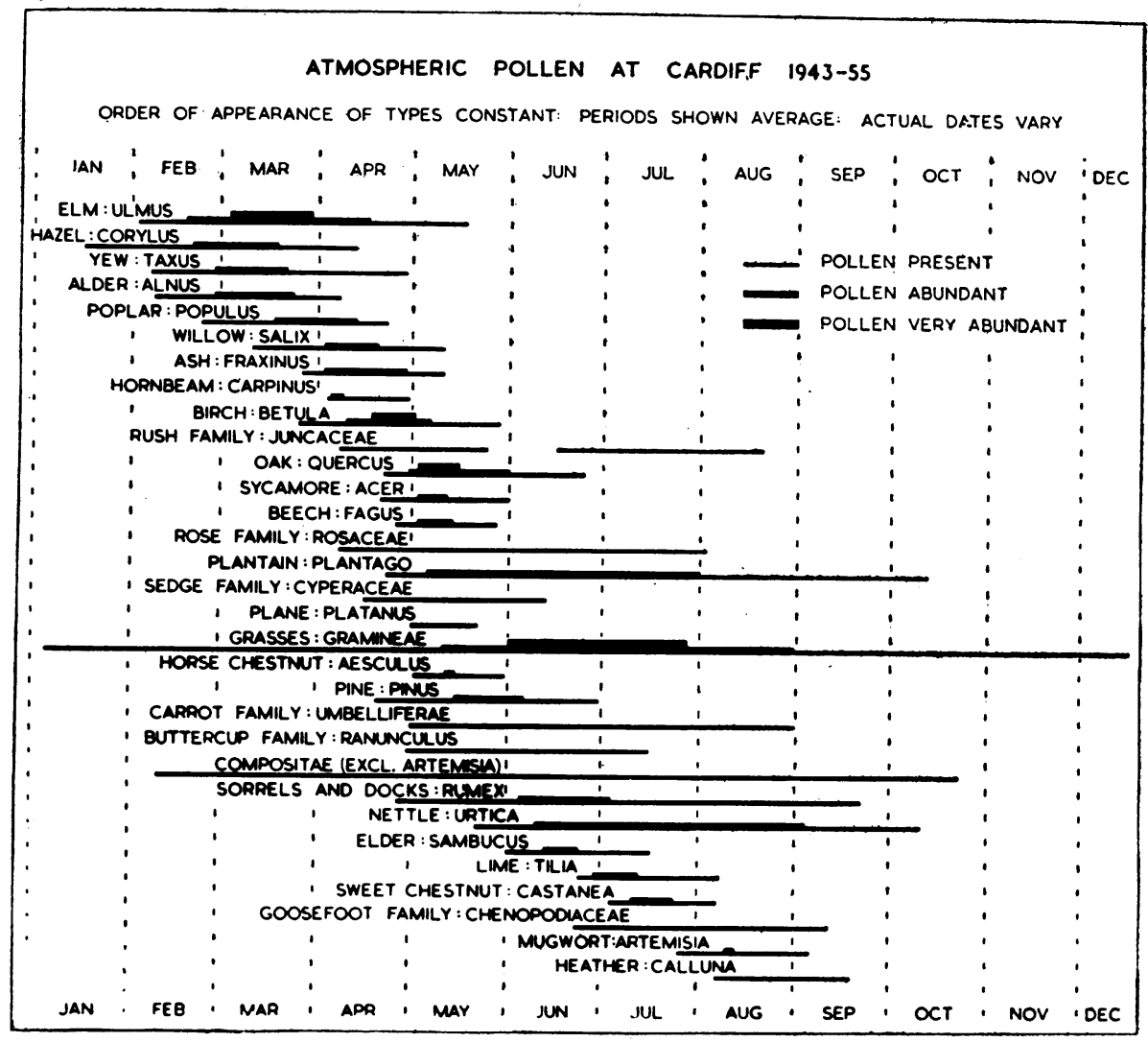

FIG. I

Of the entire pollen catch at eight stations which were surveyed in 1943 (Cardiff, Llandough, Aberystwyth, Paddington, Cambridge, Chesterfield, Edinburgh and Aberdeen), 59 per cent. of all pollen grains were grass. This is typical of the results obtained at all the stations concerned and, since it may be postulated that sensitization is most likely to be induced by those kinds of pollen which are inhaled in the largest amounts over the longest period of time, it was only to be expected that grass pollen should be found (as it has been) responsible for over 90 per cent. of all cases of pollen hay fever. The postulate stated is subject to the proviso that certain kinds of pollen are non-allergenic; but the only kind of pollen which in Britain is both abundant and virtually nonallergenic is that of pine. The distribution of hay fever plants and the incidence of grass, tree and 'weed' pollen in Great Britain have been described by Hyde in a triology of papers [Hyde, 1952, 1956, 1959(a)] which may be summarized as follows:-

\section{Grass Pollen}

The grass pollen season is fairly constant in its date from year to year: in England and Wales it lasts from the end of May to the end of July, the great bulk of the pollen ( 85 per cent. of the catch) being caught within a period of $6 \frac{1}{2}$ weeks between June I to July I 5 ; in Scotland the season is perhaps a fortnight later.

Variation in the abundance of grass pollen from year to year at a given station is considerable. At Cardiff over a period of 14 years $(1943-56)$ it has fallen as low as 46 per cent. (in 1956) and risen as high as 146 per cent. of average (in 1952). This variation has to be borne in mind when assessing results of treatment from year to year.

Locality also considerably affects pollen concentration. If the grass pollen catch on the roof of the National Museum of Wales, Cardiff ( $60 \mathrm{ft}$. above ground), be regarded as typical of the lower atmosphere in a lowland area rich in sources of grass pollen, and taken as Ioo per cent., then the incidence at other places has been found to vary from 184 per cent. ( $13 \mathrm{ft}$. above an uncut meadow) down to 23 per cent. on the Breconshire Mountains or even 14 per cent. as on Skomer Island off the west coast of Wales. Intermediate values included 40 per cent. immediately above 
the shore at Aberystwyth, 27 per cent. in central London (roof of St. Mary's Hospital, Paddington, $80 \mathrm{ft}$. above ground), and 47 per cent. at Cambridge (roof of the Botany School, $60 \mathrm{ft}$. high).

Even during the height of the pollen season, considerable daily variation may occur. The 24-hour average volumetric grass pollen counts at Cardiff on June 18 and 19, 1955, were 336 and 5 per cu.m. respectively (Hyde, I959). The hourto-hour changes are even greater: at 6 a.m. on June 21, I955, the count was 5 per cu.m., but by late afternoon on the same day it had risen to I,760 per cu.m. It has been shown that the critical factor is sunshine. On days of bright sunshine during the season there is considerable pollen in the air, especially in the late afternoons and early evenings, while during periods of dull weather little pollen occurs in the air, nor is there much during the hours of darkness. Thus, grass pollen-sensitive patients should, whenever possible, remain indoors in a closed room in the early evenings of days of bright sunshine during the grass pollen season.

\section{Tree Pollen}

The distribution of trees and woodlands in Great Britain from the point of view of allergy has been described by Hyde (I956), who has also shown that although 2 I kinds of tree pollen are more or less ubiquitous in their seasons, only seven occur in large quantities over a wide area in Great Britain, viz. alder, birch, hazel, beech, ash, oak and elm, and three others over important areas in London and south-east England, viz. hornbeam, sweet chestnut and plane. Moreover, only three have a recorded pollen incidence at all comparable with that of grass, viz. oak and elm and plane (the last named only in London).

The different kinds of tree pollen are released in the same order year after year, between February and May, but their actual dates of occurrence vary up to three weeks according to the season. All those types which from their abundance might be regarded as potential causes of allergic symptoms produce high concentrations over a period which is much shorter than the grass pollen season, viz between 7 and 21 days, according to type. Moreover, such concentrations occur in certain years only, in some species every other year, in others every three or four years; in the 'off' years the pollen counts may be so low as to be clinically of no importance. These findings explain why it is that tree pollens in this country are regarded as relatively uncommon causes of pollen hay fever and asthma. In the absence of detailed knowledge of pollen abundance season by season tree pollens present considerable diagnostic difficulties. At Cardiff birch, ash, elm and oak pollens in this order of $\frac{3}{\mathbb{D}}$ importance have been found to cause hay fever $\stackrel{\varrho}{c}$ and asthma. Sometimes the symptoms have been $\Rightarrow$

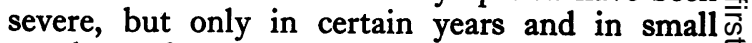
numbers of patients.

Sources of herbaceous ('weed') pollen are 듬 widespread all over Great Britain (Hyde, I959(a)), and pollens of this kind occur in the summer and $\mathbb{\otimes}$ autumn but seldom in concentrations likely to induce sensitivity in many persons. A possible exception is the pollen of stinging nettle (Urtica), $\stackrel{\circ}{\circ}$ which by the A.V.S.T. has been found to occur $\vec{\overrightarrow{ }}$ in the air in numbers approaching that of the grasses; but nettle pollen grains are very small $D$ and, if due allowance is made for this fact, the 3 maximum (bulk) incidence of nettle pollen is found to be only a small fraction of the corresponding figure for grass pollen (Hyde, unpub- 8 lished). The clinical significance of nettle pollen has not yet been established.

\section{Fungus ('Mould') Spores as Allergens}

Fungus spores were first found to be the cause of ' bronchial catarrh' by Charles Blackley (1873) when he inhaled spores of Penicillium glaucum and of Chaetomium. In therg20's, Cadham (1924\$ in Canada, Jiminez-Diaz (1924) in Spain, va Leeuwen (1924, 1925) in Holland, and Hanse (1928) in Germany pioneered the role of fungus spores as allergens. It was, however, Feinberg (1935, 1936) of Chicago who first proved that fungus spores were of considerable importance in asthma; the same author in his book later reviewed the literature and summarized his results (Feinberg, 1946). Maunsell (I954) further reviewed the literature and very recently van der Werff (1958) of Amsterdam has produced the first volume of his 'Mould Fungi and Bronchial Asthma.'

Fungus spores in the atmosphere are in general more difficult objects of study than are pollen grains. The source plants of many kinds are microscopic and therefore give no clue as to the origin of the spores when encountered in the air (whereas pollen grains of all kinds are all obviously related to their sources). Some kinds of fungus spores, e.g. Alternaria, Cladosporium and Botrytis can be readily determined as to their genus or even species, others can be determined only as belonging to large taxonomic units such as the 'sac fungi' (Ascomycetes) or the gilled-or-pored fungi (the higher Basidiomycetes), and yet others have to be placed in various 'form' genera of (probably) diverse taxonomic composition. Fungus spores in general (though with outstanding exceptions) are much smaller than most pollen grains. They are caught but very inefficiently on 'gravity' slides and when caught can 
CALENDAR OF AIRBORNE MOULDS

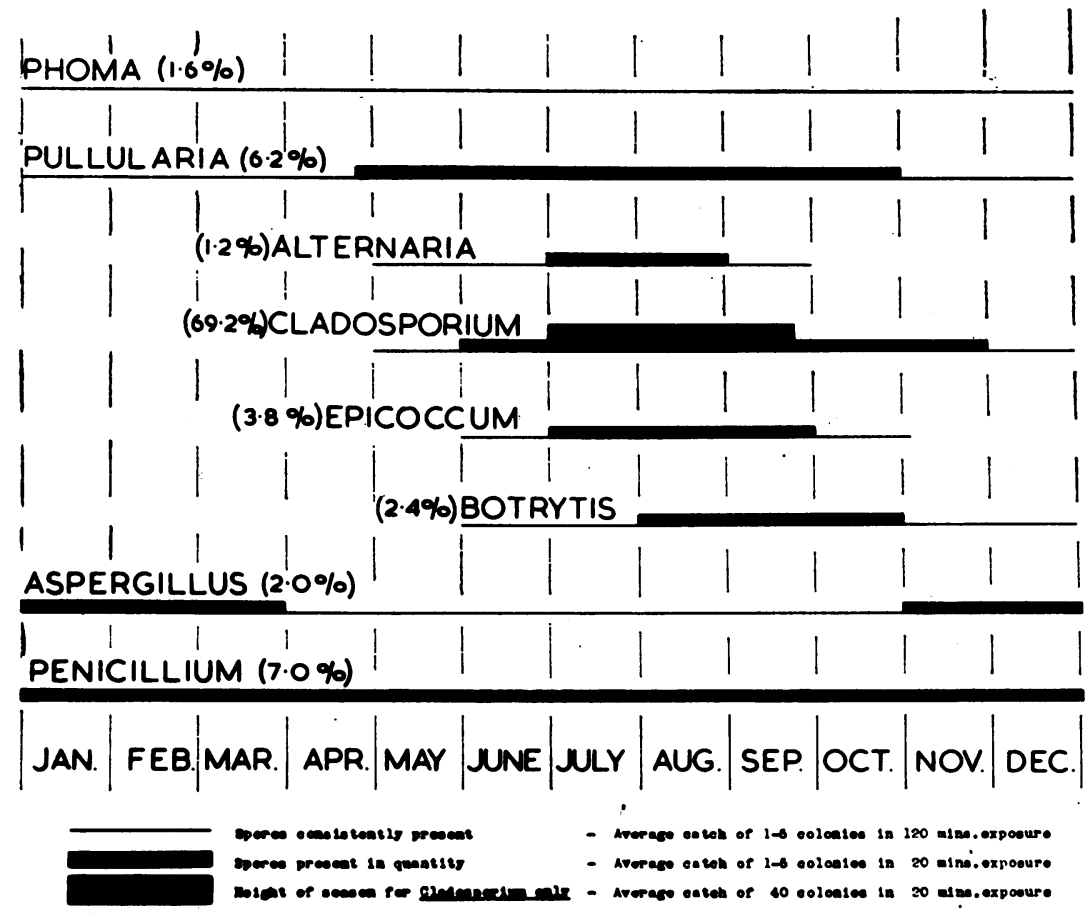

Fig. 2

only be scanned properly under an oil immersion lens.

While therefore the earliest observations on fungus spores in the air were made by crude spore-trapping methods, until recently most of the advances in this field have been made by the use of culture plates. This method as usually practised entails the exposure to the air for a short period (usually ten minutes) of a petri dish covered with Saboraud's or some other suitable medium. After five or six days the culturable spores which have been trapped have grown into colonies and, provided they are sporulating, they can be fairly easily identified at least generically. This method has been extensively used and is the basis on which the greater part of our present knowledge of fungus spores as allergens at present rests. In this country Hyde and Williams (I949) showed by this method that, while the moulds Penicillium, Pullularia, Phoma, Botrytis, Aspergillus and Alternaria occurred regularly in significant numbers, Cladosporium was by far the most abundant genus caught in the air; in fact their counts indicated a higher incidence of this mould at Cardiff than had previously been reported from any part of the world (Hyde and Williams, 1953). This survey was continued during I95I to I953 by Richards (1953), and with the assistance and collaboration of several colleagues was extended to seven other stations in Great Britain from Edinburgh in the north to Southampton in the south. It was found that 96 per cent. of the total catch at Cardiff belonged to one or other of I I genera, six of which (Cladosporium, Pullularia, Epicoccum, Botrytis, Alternaria and Candida) occurred predominantly in summer, two (Aspergillus and Oospora) were more common in winter, while the remaining three (Penicillium, Phoma and Sporotrichum) showed no seasonal variation. At other stations in Britain the botanical findings were similar, but with two outstanding quantitative differences, viz. that Cladosporium was much more abundant in rural areas than urban ones, and that Penicillium, though nowhere as abundant as Cladosporium, was commoner in large towns than elsewhere. Fig. 2 shows the mould spore calendar drawn up by Richards (1954). Later observations at Cardiff (1954-58) have indicated wide variations (from 50 to 200 per cent. of average) in annual abundance of the principal moulds caught (Hyde, unpublished). Very high concentrations of Cladosporium spores during summer have also been observed in various other parts of Great Britain (Gregory, 1952; Ainsworth, 1952; Hirst, 1953; Hamilton, 1955).

Before they began their culture plate survey, 
Hyde and Williams (r946) had made daily counts of Alternaria spores caught from the air on horizontal slides at Llandough, near Cardiff, during the two years 1942-43 and had concluded that this mould (which is regarded as an important allergen in the American Middle West) might fairly be suspected of causing allergic manifestations during late summer. Later gravity slide counts, covering, seven stations from one to 12 years each, have confirmed the ubiquity of Alternaria and its special abundance in cerealgrowing areas (Hyde, unpublished). But it is only since the Hirst trap came into use that full and proper surveys of atmospheric fungus spores in general have become possible. This apparatus enables the operator to trap fungus spores with high efficiency, to relate the catch to time of day and to state the results in terms of spore content per unit volume (Hirst, 1952, 1953). It has been used to sample fungus spores at various places in Great Britain (Gregory and Hirst, 1952, 1957; Hirst, I953; Gregory and Sreeramulu, I958; Hamilton, 1959).

Basidiospores have been shown by this means to occur in the air in such abundance as to merit serious consideration as allergens (Gregory and Hirst, I952) and one kind, namely, Merulius lacrymans (dry rot), has been proved to be antigenic (Frankland and Hay, 195I). Gregory and Hirst (1957) have shown that in the summer hyaline basidiospores (chiefly Sporobolomyces) made up $3^{I}$ per cent. of the total (numerical) catch, as against Cladosporium 46 per cent. and pollen I per cent., but the spores are much smaller than Cladosporium and very much smaller than pollen. Their clinical importance has not yet been assessed.

Much less is known of the mould flora of the indoor air of houses and factories than of outdoor air. Disturbances of bedding and similar operations cause a marked rise in the numbers of spores in the surrounding air (Maunsell, 1952). Otherwise the mould aerospora of a normally dry house is only a pale reflection of the outdoor aerospora [Richards, 1954(a)]. A special occupational risk is sensitivity to Cladosporium fulvum, a species which is antigenically distinct from Cladosporium herbarum and affects workers growing tomatoes in greenhouses. van der Werff (1958) has drawn attention to the danger of sensitization in individuals employed in factories where fungi are used for industrial purposes.

Clinical investigations have shown that many cases of summer asthma are due to sensitivity to certain kinds of fungus spores, particularly those of saprophytic moulds. This applies especially to Cladosporium herbarum, to a lesser extent to Alternaria and Botrytis, occasionally to Pullularia, Epicoccum and Candida and very rarely to Peni- $\frac{\bar{\alpha}}{c}$
cillium.

This subject is still at present but partly under- $\overrightarrow{\vec{F}}$ stood. But enough botanical work has already $\stackrel{?}{+}$ been done to have given clinicians a lead on certain kinds of fungus spores, and the further botanical studies and clinical work now in progress $\frac{\bar{T}}{\bar{\phi}}$ will doubtless throw more light on the situation.

The assistance of $\mathrm{Mr}$. George Smith in the os determination of moulds is gratefully acknow- $\vec{\circ}$ ledged.

\section{BIBLIOGRAPHY}

AINSWORTH, G. C. (1952), f. gen. Microbiol., 7, 359.

BLACKLEY, CHARLES (1873), 'Experimental Research on the Cause and Nature of Catarrhus Aestivus,' Bailliere, Tindall
$\&$ Cox, London.

CADHAM, F. T. (1924), f. Amer. med. Ass., 83, 27.

ERDTMAN, G. (1943), 'An Introduction to Pollen Analysis, Chronica Botanica Co., Waltham, Mass.

ERDTMAN, G. (1952), 'Pollen Morphology and Plant Taxonomy: I-Angiosperms,' Almquist \& Wiksell, Stockholm.

FAEGRI, K., and IVERSEN, J. (1950), 'Textbook of Modern Pollen Analysis,' Munksgaard, Copenhagen.

FEINBERG, S. M. (1935), Wis. med. F., 34, 254.

FEINBERG, S. M. (1936), f. Amer. med. Ass., 107, 186r. FEINBERG, S. M. (1946), 'Allergy in Practice,' Year Book Co.
Chicago.

FRANKLAND, A. W., and HAY, M. H. (195I), Acta allerg. (Kbh.), iv, 186.

GREGORY, P. H. (1952), Nature, 170, 475.

GREGORY, P. H., and HIRST, J. M. (1952), Nature, 170, 414.

GREGORY, P. H., and HIRST, J. M. (I957), F. gen. Microbiotg I7, 135 .

GREGORY, P. H., and SREERAMULU, T. (1958), Trans. Bric mycol. Soc., 4I, 145.

HAMILTON, E. D. (1955), Acta allerg. (Kbh.), 9, 235.

HAMILTON, E. D. (1959), Acta allerg. (Kbh.), xiii, 143-175.

HANSEN, K. (1928), Verh. dtsch. Ges. inn. Med., 40, 204.

HIRST, J. M. (1952), Ann. app. Biol., 39, 257.

HIRST, J. M. (1953), Trans. Brit. mycol. Soc., 36, 375.

HYDE, H. A. (1950), New Phytol., 49, 3, 398.

HYDE, H. A. (1950 (a)), New Phytol., 49, 3, 407.

HYDE, H. A. (1952), Acta allerg. (Kbh.), v, 98.

HYDE, H. A. (1952 (a) ), New Phytol., 5I, 3, $28 \mathrm{r}$.

HYDE, H. A. (1955), Proc. Linn. Soc., London, 165, 107.

HYDE, H. A. (1956), Acta allerg. (Kbh.), x, 224.

HYDE, H. A. (1956), Acta allerg. (Kbh.), x, 224.

HYDE, H. A. (1959), F. Allergy, 30, 219-234.

HYDE, H. A. (1959 (a)), Acta allerg. (Kbh.), xiii, 186-209.

HYDE, H. A. (unpublished).

HYDE, H. A., and ADAMS, K. (1958), 'An Atlas of Airborne Pollen Grains,' Macmillan, London.

HYDE, H. A., RICHARDS, M., and WILLIAMS, D. A. (1956), B.M.广̈., 4972, 886-890.

HYDE, H. A., and WILLIAMS, D. A. (1946), Brit. mycol. Soc., xxix, parts I and II, 78 .

HYDE, H. A., and WILLIAMS, D. A. (1949), Nature, 164, 668.

HYDE, H. A., and WILLIAMS, D. A. (1953), Trans. Brit. mycol. Soc., 36, 3, 260.

JIMENEZ-DIAZ, C., and SANCHEZ CUENCA, F. (1924), Arch. Med. Cirug. (Madrid), 29, 284.

MAUNSELL, K. (1952), Int. Arch. Allergy, 3, 93.

MAUNSELL, K. (1954), Progr. Allergy, iv, 457.

PEARSON, R. S. B. (I958), Acta allerg. (Kbh.), xil, 277.

RICHARDS, M. (1953), Nature, I71, 615.

RICHARDS, M. (1954), Acta allerg. (Kbh.), vii, 357.

RICHARDS, M. (1954 (a) ), ₹. Allergy, 25, 429.

VAN DER WERFF, P.J.' (1958), 'Mould Fungi and Bronchial Asthma,' Vol. I, Leiden, Stenfert Kroese, N.V.

VAN LEEUWWEN, 'W. S. (1924), Proc. Roy. Soc. Med. (Sect. Therap and Pharmacol.), 17, 19.

VAN LEEUWEN, W. S. (1925), 'Allergic Diseases,' J. B. Lippincott Co., Philadelphia.

WODEHOUU'SE, R. P. (1935), 'Pollen Grains,' McGraw-Hill, New York.

WILLIAMS, D. A. (1958), Proc. 3rd Internat. Congress Allergy,

WILLIAM, Flammarion, Paris. and JACOBS, J.' (1958), Acta allerg. (Kbh.), xii, 376. 